\title{
Outpatient management of transient ischaemic attack
}

\author{
Victor Weng Keong Loh ${ }^{1}$, MMed, MCFP, Derek Tuck Loong Soon ${ }^{2}$, MBBChir, PhD, Leonard Leong Litt $\underline{\text { Yeo }}^{2}$, MBBS, MRCP
}

\begin{abstract}
Mr Chong, a 63-year-old retired, right-handed Chinese man, hurriedly walked over to your clinic after feeling a sudden, transient episode of weakness in his left arm and face. He had noticed the weakness on waking that morning. At first, he could hardly raise his shoulder, and was only able to move his fingers with great difficulty. About 15 minutes later, while trying to get dressed, he noticed the strength in his arm returning and his face returning to normal. He had been on amlodipine for hypertension and simvastatin for hyperlipidaemia over the past two years, and had been smoking for the past ten years. He apologetically admitted that he had run out of medication two weeks ago. His blood pressure was $170 / 100 \mathrm{mmHg}$ and his heart rate was regular at $88 \mathrm{beats} / \mathrm{min}$. You noted that his speech was clear and gait normal. On further neurological examination, neither upper or lower limb weakness nor numbness was detected bilaterally, and there were no signs of cerebellar dysfunction.
\end{abstract}

\section{WHAT IS A TRANSIENT ISCHAEMIC ATTACK?}

The definition of transient ischaemic attack (TIA) has evolved over the past few decades. Classically, a TIA was defined as a sudden, focal neurological deficit of less than 24 hours in duration. This definition has evolved to incorporate ongoing advances in neuroimaging and acute stroke protocols. For instance, $30 \%-50 \%$ of patients diagnosed to have TIA using the classical 'time-based' criteria were found to have central nervous system (CNS) infarction on diffusion-weighted magnetic resonance imaging (MRI). ${ }^{(1)}$ More recently, the 2009 American Heart Association/American Stroke Association's 'tissuebased' definition of TIA stated that it is "a transient episode of neurological dysfunction caused by focal brain, spinal cord or retinal ischaemia without acute infarction" ${ }^{\prime \prime}{ }^{(1)}$

The diagnosis of CNS infarction is based both on careful clinical assessment and evidence on advanced neuroimaging. ${ }^{(2)}$ Early neuroimaging is crucial, as it affects decision-making on time-sensitive interventions in acute stroke management. On MRI, a lack of evidence of infarction in patients with symptoms of cerebral ischaemia distinguishes a TIA from an acute ischaemic stroke. In cases where advanced neuroimaging is not available, CNS infarction is diagnosed when focal neurological deficits persist for 24 hours or more, or until death, whichever is earlier. Proper documentation of evidence for diagnosing TIA or acute stroke is important in view of medicolegal ramifications in insurance claims. TIA and acute ischaemic stroke are part of the cerebral ischaemia spectrum. TIA represents a milder event in which neurological cell death or infarction has not yet occurred, and thus may be prevented.

\section{HOW RELEVANT IS THIS TO MY PRACTICE?}

Stroke is a devastating disease. In 2014, it was the fourth most common cause of mortality in Singapore $(8.4 \%) .{ }^{(3)}$ In that year, the total number of stroke episodes among Singapore residents in public hospitals was almost 7,000; of these, $81.2 \%$ were ischaemic strokes, $15.5 \%$ were intracerebral haemorrhages and $3.1 \%$ were subarachnoid haemorrhages. ${ }^{(4)}$ In 2010, stroke held third position $(6.8 \%)$ in terms of contribution to disabilityadjusted life years. ${ }^{(5)}$ Stroke has an incidence of 1.8 per 1,000 person-years and a prevalence of $3.7 \%$ in Singapore. ${ }^{(6)}$ With an estimated expenditure of almost SGD12,500 per patient per year, ${ }^{(7)}$ stroke is a disease that exacts a substantial financial burden in addition to the heavy physical, emotional, and psychosocial costs that patients and family members often need to grapple with.

TIAs are early warnings that signal a high risk for further ischaemic events as well as the need for aggressive intervention to prevent permanent cerebral infarction and the accompanying disability. $7 \%-40 \%$ of patients who present with stroke have had a prior TIA. Similarly, $10 \%-15 \%$ of patients with TIA have the risk of a stroke occurring within three months; half of these strokes occur within 48 hours from the onset of TIA symptoms. ${ }^{(1)}$

\section{Risk factors for TIA}

Both TIAs and acute ischaemic strokes occur because of cerebral ischaemia and are associated with vascular risk factors. ${ }^{(3,8,9)}$ Table I summarises the established modifiable risk factors of TIA and acute ischaemic stroke.

${ }^{1}$ Division of Family Medicine, ${ }^{2}$ Division of Neurology, University Medicine Cluster, National University Health System, Singapore

Correspondence: Dr Victor Weng Keong Loh, Consultant Family Physician, Division of Family Medicine/Neurology, University Medicine Cluster, National University Health System, 1E Kent Ridge Road, Singapore 119228. victor_loh@nuhs.edu.sg 


\section{Non-modifiable risk factors}

The median age of stroke was 67 years in 2014. ${ }^{(3)}$ Apart from age, other non-modifiable risk factors include male gender, a past history of ischaemic heart disease, a family history of stroke or TIA, and Malay ethnicity. In 2014, the age-standardised incidence rate per 100,000 population for stroke in the 25-64 year age group was highest for individuals of Malay ethnicity (233.4) compared to those of Indian (173.4) and Chinese (134.3) ethnicity. ${ }^{(3)}$

\section{Modifiable risk factors}

Primary care plays a crucial role in the prevention of TIA and stroke. Hypertension, hyperlipidaemia and diabetes mellitus (Table I), which are conditions covered by the Community Health Assist Scheme and Chronic Disease Management Programme, comprise three of the top four conditions seen at local polyclinics. ${ }^{(10)}$ The 2010 INTERSTROKE study found that five modifiable risk factors (hypertension, current smoking, abdominal obesity, unhealthy diet and physical inactivity) accounted for more than $80 \%$ of strokes. ${ }^{(11)}$

\section{RECOGNISING TIA/ACUTE STROKE}

\section{History-taking}

The assessment of a patient with TIA or stroke includes a careful history of the temporal sequence (onset and progression), neurological deficit, handedness (95\% of right-handed individuals have the left hemisphere as their dominant lobe), vascular risk factors, and premorbid functional status of the patient. The temporal sequence is particularly important in view of the timecritical management of patients with acute ischaemic stroke, as every effort should be made to rush such patients to a tertiary hospital with stroke treatment facilities. It is important to educate the patient that the sudden loss of neurological function from cerebral ischaemia may be noticed on awakening, or while in the middle of any daily activity. While the focal neurological deficits persist in patients with stroke, those with TIA experience recovery of function; $60 \%$ of TIAs last for less than one hour, $71 \%$ last for less than two hours and $14 \%$ last for more than six hours. ${ }^{(1)}$ In any case, the patients should not wait for their symptoms to improve, but should seek help immediately.

\section{Physical examination}

A focused physical examination includes: (a) an assessment of the patient's state of consciousness and blood pressure; (b) a cardiovascular examination that looks for atrial fibrillation and cervical bruits; and (c) a thorough neurological examination to document any neurological deficit. By definition, the neurological deficits seen in a TIA do not last for more than 24 hours, and may have resolved at the time of consultation. The absence of detectable neurological deficits does not exclude an ischaemic event or absolve the patient from the need for an urgent neurological consult. Table II summarises the common neurological findings in a patient with stroke.

\section{Stroke mimics}

In a 2006 study, up to $31 \%$ of patients initially diagnosed as having stroke were later found to have a stroke mimic. Table III
Table I. Established modifiable risk factors of transient ischaemic attack and stroke.

\begin{tabular}{lcc}
\hline Parameter & Prevalence $^{*}\left(\mathbf{O}^{(9)}\right)$ & $\begin{array}{c}\text { Odds ratio of cerebral } \\
\text { ischaemia }\end{array}$ \\
\hline $\begin{array}{l}\text { Modifiable risk factor } \\
\text { Hypertension }\end{array}$ & 23.5 & 2.64 \\
Diabetes mellitus & 11.3 & 1.36 \\
Hyperlipidaemia & 17.4 & - \\
Obesity & $10.8^{\dagger}$ & $1.65^{\ddagger}$ \\
Smoking & 14.3 & 2.09 \\
Atrial fibrillation & - & - \\
Unhealthy diet & - & 1.35 \\
Psychosocial stress & - & 1.30 \\
High alcohol intake & - & 1.51 \\
Protective factor & & 0.69 \\
Regular physical & - & \\
activity & & \\
\hline
\end{tabular}

*Prevalence among adults aged $18-69 \mathrm{yr}(2010) .{ }^{\dagger}$ Body mass index $\geq 30 \mathrm{~kg} / \mathrm{m}^{2}$. ‡Elevated waist-to-hip ratio.

Table II. Common transient ischaemic attack/stroke symptoms and location of ischaemia.

\begin{tabular}{|c|c|}
\hline Neurological symptom & Location \\
\hline $\begin{array}{l}\text { Unilateral weakness } \\
\text { (facial, hemiparesis) }\end{array}$ & $\begin{array}{l}\text { Contralateral internal capsule, corona } \\
\text { radiata }\end{array}$ \\
\hline Unilateral sensory loss & Contralateral thalamus \\
\hline Speech disturbance & $\begin{array}{l}\text { Dominant hemisphere } \\
\text { (frontal/temporal lobe) }\end{array}$ \\
\hline $\begin{array}{l}\text { Visual-spatial-perceptual } \\
\text { dysfunction }\end{array}$ & Contralateral hemisphere \\
\hline Monocular blindness & Ipsilateral retina or optic nerve \\
\hline Hemianopia & $\begin{array}{l}\text { Contralateral occipital lobe, optic } \\
\text { radiation }\end{array}$ \\
\hline Diplopia & Oculomotor pathways (midbrain/pons) \\
\hline Ataxia, incoordination & Cerebellum \\
\hline Giddiness, vertigo & Vestibulocerebellum, brainstem \\
\hline Crossed symptoms/signs & Brainstem \\
\hline
\end{tabular}

shows these common stroke mimics and their frequency of occurrence. ${ }^{(12)}$ Factors that increase the likelihood of a mimic include: cognitive impairment, loss of consciousness, confusion, an initial seizure and the absence of lateralising signs. Nevertheless, most patients presenting with stroke mimics still require referral to a hospital for appropriate investigations.

In comparison, factors that increase the likelihood of a definite stroke include: definite focal neurological symptoms, a definite time of onset, and the presence of definite focal neurological signs. Capillary glucose testing should be performed to rule out hypoglycaemia (metabolic cause) in the outpatient setting.

\section{FAST}

FAST (Box 1), which was developed from the three-item reproducible Cincinnati Prehospital Stroke Scale, ${ }^{(13)}$ is an easyto-remember public education tool for early stroke recognition. It has been validated for identifying anterior circulation strokes, which are most amenable to thrombolytic therapy. A 2012 study of 
residents in Bishan town, Singapore, ${ }^{(14)}$ showed poor stroke literacy, with only $47.6 \%$ of respondents being able to cite at least one of the FAST warning signs associated with stroke. Physicians should educate and prepare at-risk patients and their family on the use of FAST to recognise and respond to acute stroke if the need arises.

Box 1. The FAST mnemonic for recognising stroke:

- Facial drooping: One side of the face does not move as well as the other side (forehead, eyes, mouth).

- Arm weakness: Unilateral weakness or positive pronator drift.

- Speech difficulty: Slurring of speech, wrong words or unable to speak.

- Time: A patient with any of the above should be sent to hospital immediately.

\section{Risk stratification}

The $\mathrm{ABCD}^{2}$ score $^{(15)}$ was developed to determine stroke risk following a TIA (Table IV). The risk of stroke within two days of a TIA is determined using a point system: 1 to 3 points - low risk $(1 \%)$; 4 or 5 points - moderate risk $(4.1 \%) ; 6$ or 7 points - high risk $(8.1 \%)$. The score may be used in primary care to decide the urgency of neurological review, and at the emergency department to decide which department the patient should be admitted to, the urgency of investigations and the selection of treatment.

\section{WHAT CAN I DO IN MY PRACTICE?}

\section{Immediate management}

The maxim 'time is brain' is pertinent in acute stroke management. The effectiveness of interventions such as recombinant tissue plasminogen activator (rTPA) therapy (4.5-hour window from onset) and endovascular procedures (6-8-hour window from onset $)^{(16,17,18)}$ depends on a number of factors, including appropriate patient selection and time from onset of symptoms in a patient with acute ischaemic stroke. Prehospital management is thus geared toward timely delivery of patients to acute stroke units so that rapid assessment can be made in accordance with the 'stroke chain of survival' (Box 2). ${ }^{(19)}$ Practical steps before the arrival of emergency medical services include stabilisation of the patient, checking for hypoglycaemia, cardiac monitoring and establishing intravenous access. Any lowering of elevated blood pressure should be accomplished only after hospital arrival.

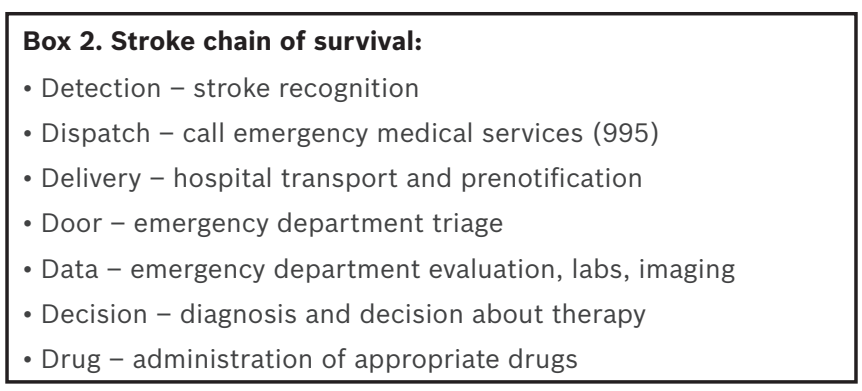

\section{Hospital/inpatient assessment}

All patients with TIA or acute stroke should undergo computed tomography or MRI of the brain as soon as possible, preferably within 24 hours. As selective carotid artery intervention has been shown to be effective, post-TIA and post-stroke patients
Table III. Common stroke mimics. ${ }^{(12)}$

\begin{tabular}{lc}
\hline Condition & Frequency (\%) \\
\hline Seizure & 21.1 \\
Sepsis & 12.8 \\
Toxic/metabolic & 11.0 \\
Space-occupying lesion & 9.2 \\
Acute confusional state & 6.4 \\
Vestibular dysfunction & 6.4 \\
Acute mononeuropathy & 5.5 \\
\hline
\end{tabular}

Table IV. $A B C D^{2}$ scoring system for assessing stroke risk after a transient ischaemic attack (TIA). ${ }^{(15)}$

\begin{tabular}{lc}
\hline Characteristic & Point \\
\hline Age 60 yr & 1 \\
Blood pressure & 1 \\
Systolic $\geq 140 \mathrm{mmHg}$ & \\
Diastolic $\geq 90 \mathrm{mmHg}$ & \\
Clinical presentation & \\
Unilateral weakness & 2 \\
Speech impairment without weakness & 1 \\
Diabetes mellitus & 1 \\
Duration of TIA (min) & \\
$\geq 60$ & 2 \\
$10-59$ & 1 \\
\hline
\end{tabular}

should be assessed for treatable atherosclerotic lesions of the cervicocephalic vasculature. Cardiac assessment is also required to exclude any cardioembolic source and/or atrial fibrillation. All patients should be screened for modifiable risk factors (Table I). Select patient groups, such as young patients, should be screened for rarer causes.

\section{Secondary stroke prevention}

After the inpatient review, primary care physicians provide continuity of care by addressing the modifiable risk factors of TIA and stroke (Table I). Significant relative risk reduction of stroke may be achieved with high-intensity physical activity $(64 \%)$, (20) blood pressure control $(30 \%-40 \%)$, $^{(21,22)}$ statin therapy $(16 \%-33 \%),{ }^{(23,24)}$ and antiplatelet agents $(18 \%-37 \%){ }^{(25,26)}$

High-intensity lipid-lowering therapy, ${ }^{(27)}$ in accordance with the 2013 American College of Cardiology/American Heart Association guidelines, is recommended for patients with ischaemic stroke or TIA. Aspirin, extended-release dipyridamole/aspirin or clopidogrel are acceptable as first-line antiplatelet agents, ${ }^{(28)}$ and long-term anticoagulation with warfarin (international normalised ratio range 2.0-3.0) or novel oral anticoagulants may be required for patients who have atrial fibrillation.

\section{Patient education}

The FAST mnemonic (Box 1) is an easy-to-remember tool to educate patients and family members in stroke and TIA recognition. Patients need to be educated to head directly to the emergency department (i.e. bypassing primary care) when acute stroke is suspected. 
Mr Chong dropped by your clinic with his wife. He reported that after he left your clinic in the ambulance, he was admitted to the hospital for further investigations and was discharged one week ago. He underwent a CT scan of the head, which excluded any intracranial bleeding, while MRI did not detect any cerebral infarct or haemorrhage. Examining his discharge summary, you noted that carotid ultrasonography and transcranial Doppler showed mild stenosis of the right internal carotid artery. He was thankful that he survived the TIA without any neurological deficit. His current blood pressure was $130 / 80 \mathrm{mmHg}$ and his neurological examination was normal. He was put on aspirin, enalapril and atorvastatin. Mr Chong no longer smokes and has promised to adhere to the medicines prescribed. He has signed up for regular tai chi lessons at a nearby community centre.

ABSTRACT Stroke is a significant cause of death and disability in Singapore; in 2014, it was the fourth most common cause of death. Transient ischaemic attack (TIA) is defined as a transient episode of neurological dysfunction caused by focal brain, spinal cord or retinal ischaemia without evidence of acute infarction. The diagnosis of TIA/acute stroke needs to be considered in all patients who present with sudden focal neurological dysfunction. Prompt referral for assessment, neuroimaging and intervention provides the best chance for neurological recovery and/or minimising further neurological damage. Primary care physicians have a crucial role in TIA/stroke prevention and management. This includes referring patients with suspected acute TIA/stroke to hospitals with stroke treatment facilities immediately; managing the modifiable risk factors of cerebral ischaemia; continuing prescription of antiplatelet agents and/or anticoagulation where indicated; and teaching patients to recognise and respond to suspected cerebral ischaemia using the FAST (face, arm, speech, time) acronym.

Keywords: ischaemic stroke, outpatient, TIA

\section{TAKE HOME MESSAGES}

1. TIA is defined as a transient episode of neurological dysfunction caused by neurological ischaemia without evidence of acute infarction. All patients with suspected TIA or stroke should have their capillary glucose measurement and a quick $A B C D^{2}$ score taken, with early neurological imaging, preferably within 24 hours from the onset of symptoms.

2. Patients with an acute loss of focal neurological function may be having a TIA or acute stroke. The physician should immediately refer patients with suspected TIA or stroke to an acute stroke unit for neuroimaging, assessment and aggressive vascular risk reduction, and recommend time- sensitive interventions for acute ischaemic stroke (rTPA and endovascular procedures) that were proven to be effective.

3. Primary care physicians play an important role in the prevention of subsequent stroke by managing vascular risk factors (Table I), encouraging patients to adopt lifestyle measures (e.g. exercise, diet and smoking cessation) and continuing antiplatelet therapy (or anticoagulation for those with atrial fibrillation).

4. FAST (face, arm, speech, time) is an effective public education tool for the recognition of anterior circulation stroke.

\section{REFERENCES}

1. Easton JD, Saver JL, Albers GW, et al; American Heart Association; American Stroke Association Stroke Council; Council on Cardiovascular Surgery and Anesthesia; Council on Cardiovascular Radiology and Intervention; Council on Cardiovascular Nursing; Interdisciplinary Council on Peripheral Vascular Disease. Definition and evaluation of transient ischemic attack: a scientific statement for healthcare professionals from the American Heart Association/American Stroke Association Stroke Council; Council on Cardiovascular Surgery and Anesthesia; Council on Cardiovascular Radiology and Intervention; Council on Cardiovascular Nursing; and the Interdisciplinary Council on Peripheral Vascular Disease. The American Academy of Neurology affirms the value of this statement as an educational tool for neurologists. Stroke 2009; 40:2276-93.

2. Sacco RL, Kasner SE, Broderick JP, et al; American Heart Association Stroke Council, Council on Cardiovascular Surgery and Anesthesia; Council on Cardiovascular Radiology and Intervention; Council on Cardiovascular and Stroke Nursing; Council on Epidemiology and Prevention; Council on Peripheral Vascular Disease; Council on Nutrition, Physical Activity and Metabolism. An updated definition of stroke for the 21 st century: a statement for healthcare professionals from the American Heart Association/American Stroke Association. Stroke 2013; 44:2064-89.

3. Ministry of Health, Singapore. Principal causes of death [online]. Available at: https://www.moh.gov.sg/content/moh_web/home/statistics/ Health_Facts_Singapore/Principal_Causes_of_Death.html. Accessed June 20, 2016

4. National Registry of Diseases Office, Ministry of Health, Singapore. Stroke Registry Report 2014 [online]. Available at: https://www.nrdo.gov.sg/ docs/librariesprovider3/default-document-library/stroke-report-2014. pdf?sfvrsn=0. Accessed June 20, 2016.

5. Epidemiology and Disease Control Division, Ministry of Health, Singapore. Singapore Burden of Disease Study 2010 [online]. Available at: https:// www.moh.gov.sg/content/dam/moh_web/Publications/Reports/2014/ Singapore\%20Burden $\% 20$ of $\% 20$ Disease $\% 20$ Study $\% 202010 \% 20$ Report_v3.pdf. Accessed June 20, 2016.

6. Venketasubramanian N, Chen CL. Burden of stroke in Singapore. Int J Stroke 2008; 3:51-4

7. $\mathrm{Ng}$ CS, Toh MP, Ng J, Ko Y. Direct medical cost of stroke in Singapore. Int J Stroke 2015; 10 Suppl A100:75-82.

8. Goldstein LB, Bushnell CD, Adams RJ, et al; American Heart Association Stroke Council; Council on Cardiovascular Nursing; Council on Epidemiology and Prevention; Council for High Blood Pressure Research; Council on Peripheral Vascular Disease, and Interdisciplinary Council on Quality of Care and Outcomes Research. Guidelines for the primary prevention of stroke: a guideline for healthcare professionals from the American Heart Association/American Stroke Association. Stroke 2011; 42:517-84.

9. Ministry of Health, Singapore. Disease burden [online]. Available at: https://www.moh.gov.sg/content/moh_web/home/statistics/Health_Facts_ Singapore/Disease_Burden.html. Accessed June 20, 2016.

10. Ministry of Health, Singapore. Top 4 conditions of polyclinic attendances. [online]. Available at: https://www.moh.gov.sg/content/moh_web/home/ statistics/Health_Facts_Singapore/Top_4_Conditions_of_Polyclinic_ Attendances.html. Accessed June 20, 2016.

11. O'Donnell MJ, Xavier D, Liu L, et al; INTERSTROKE investigators. Risk factors for ischaemic and intracerebral haemorrhagic stroke in 22 countries (the INTERSTROKE study): a case-control study. Lancet 2010; 376:112-23. 
12. Hand PJ, Kwan J, Lindley RI, Dennis MS, Wardlaw JM. Distinguishing between stroke and mimic at the bedside: the brain attack study. Stroke 2006; 37:769-75

13. Kothari RU, Pancioli A, Liu T, Brott T, Broderick J. Cincinnati Prehospita Stroke Scale: reproducibility and validity. Ann Emerg Med 1999; 33:373-8.

14. Lim W, Chuang DF, Chue KM, et al. Stroke literacy in Singapore: data from a survey of public housing estate residents. Ann Acad Med Singapore 2014; 43:454-63.

15. Johnston SC, Rothwell PM, Nguyen-Huynh MN, et al. Validation and refinement of scores to predict very early stroke risk after transient ischaemic attack. Lancet 2007; 369:283-92.

16. Venketasubramanian N, Pwee KH, Chen CP; Singapore Ministry of Health Clinical Practice Guidelines Workgroup on Stroke and Transient Ischaemic Attacks. Singapore ministry of health clinical practice guidelines on stroke and transient ischemic attacks. Int J Stroke 2011; 6:251-8.

17. Goyal M, Demchuk AM, Menon BK, et al; ESCAPE Trial Investigators Randomized assessment of rapid endovascular treatment of ischemic stroke. N Engl J Med 2015; 372:1019-30.

18. Ciccone A, Valvassori L, Nichelatti $M$, et al; SYNTHESIS Expansion Investigators. Endovascular treatment for acute ischemic stroke. N Engl Med 2013; 368:904-13.

19. Adams HP Jr, del Zoppo G, Alberts MJ, et al; American Heart Association/ American Stroke Association Stroke Council; American Heart Association/ American Stroke Association Clinical Cardiology Council; American Heart Association/American Stroke Association Cardiovascular Radiology and Intervention Council; Atherosclerotic Peripheral Vascular Disease Working Group; Quality of Care Outcomes in Research Interdisciplinary Working Group. Guidelines for the early management of adults with ischemic stroke: a guideline from the American Heart Association/ American Stroke Association Stroke Council, Clinical Cardiology Council, Cardiovascular Radiology and Intervention Council, and the Atherosclerotic Peripheral Vascular Disease and Quality of Care Outcomes in Research Interdisciplinary Working Groups: The American Academy of Neurology affirms the value of this guideline as an educational tool for neurologists. Circulation 2007; 115:e478-534.
20. Lee CD, Folsom AR, Blair SN. Physical activity and stroke risk: a metaanalysis. Stroke 2003; 34:2475-81.

21. Rashid P, Leonardi-Bee J, Bath P. Blood pressure reduction and secondary prevention of stroke and other vascular events: a systematic review. Stroke $2003 ; 34: 2741-8$.

22. Lawes CM, Bennett DA, Feigin VL, Rodgers A. Blood pressure and stroke: an overview of published reviews. Stroke 2004; 35:1024

23. Amarenco P, Bogousslavsky J, Callahan A 3rd, et al; Stroke Prevention by Aggressive Reduction in Cholesterol Levels (SPARCL) Investigators. High-dose artovastatin after stroke or transient ischemic attack. N Eng J Med 2006; 355:549-59

24. Amarenco P, Goldstein LB, Szarek M, et al; SPARCL Investigators. Effects of intense low-density lipoprotein cholesterol reduction in patients with stroke or transient ischemic attack: the Stroke Prevention by Aggressive Reduction in Cholesterol Levels (SPARCL) trial. Stroke 2007; 38:3198204

25. Verro P, Gorelick PB, Nguyen D. Aspirin plus dipyridamole versus aspirin for prevention of vascular events after stroke or TIA: a meta-analysis. Stroke 2008; 39:1358-63.

26. Diener HC, Cunha L, Forbes C, et al. European stroke prevention study. 2. Dipyridamole and acetylsalicylic acid in the secondary prevention of stroke. J Neurol Sci 1996; 143:1-13.

27. Stone NJ, Robinson JG, Lichtenstein $\mathrm{AH}$, et al; American College of Cardiology/American Heart Association Task Force on Practice Guidelines. 2013 ACC/AHA guideline on the treatment of blood cholesterol to reduce atherosclerotic cardiovascular risk in adults: a report of the American College of Cardiology/American Heart Association Task Force on Practice Guidelines. J Am Coll Cardiol 2014; 63(25 Pt B):2889-934.

28. Kernan WN, Ovbiagele B, Black HR, et al; American Heart Association Stroke Council, Council on Cardiovascular and Stroke Nursing, Council on Clinical Cardiology, and Council on Peripheral Vascular Disease. Guidelines for the prevention of stroke in patients with stroke and transient ischemic attack: a guideline for healthcare professionals from the American Heart Association/American Stroke Association. Stroke 2014; 45:2160-236 


\section{SINGAPORE MEDICAL COUNCIL CATEGORY 3B CME PROGRAMME} (Code SMJ 201612A)

1. Stroke is a debilitating disease that is the fourth most common cause of death in Singapore.

2. All patients diagnosed with a transient ischaemic attack (TIA) based on the reversal of focal neurological deficits within 24 hours have no evidence of cerebral infarction on neuroimaging.

3. Ischaemic strokes account for $40 \%-50 \%$ of strokes that occur in Singapore.

4. TIAs are early warnings that signal a need to aggressively decrease the modifiable risk factors for stroke.

5. The incidence of stroke among adults aged 25-64 years is highest among those of Chinese ethnicity compared to individuals of Malay or Indian ethnicity.

6. The median age of stroke in Singapore was 67 years in 2014.

7. Hypertension, diabetes mellitus and hyperlipidaemia are modifiable risk factors for TIA and stroke.

8. Psychosocial stress is a risk factor for stroke.

9. Smoking is not a risk factor for stroke.

10. A patient who has a suspected TIA should wait for symptoms to resolve before seeking medical attention.

11. In general, individuals who are right-handed have a dominant left hemisphere.

12. In patients suspected to have an acute stroke, capillary glucose testing should be performed.

13. Patients who are initially thought to have suffered an acute stroke, but are later found to have a stroke mimic should be referred to the hospital for appropriate further investigation.

14. FAST (face, arm, speech, time) is an easy-to-remember public education tool that has been validated for both anterior and posterior circulation strokes.

15. In general, the majority of Singaporeans are able to cite at least one of the warning signs in the FAST mnemonic.

16. The $A B C D^{2}$ score may be used to assess stroke risk following a TIA.

17. The time window for recombinant tissue plasminogen activator therapy in a patient with suspected ischaemic stroke is 4.5 hours from the onset of the stroke.

18. Patients who have just suffered a stroke and have acutely elevated blood pressure readings ( $\geq 200 / 120 \mathrm{mmHg}$ ) should have their blood pressure aggressively reduced at the primary care clinic while awaiting for emergency medical services to transport the patient to hospital.

19. In Singapore, a patient with TIA or stroke should ideally have neuroimaging performed within 24 hours of the onset of symptoms.

20. The following are acceptable as first-line antiplatelet agents in patients with stroke: aspirin, dipyridamole/ aspirin, or clopidogrel.

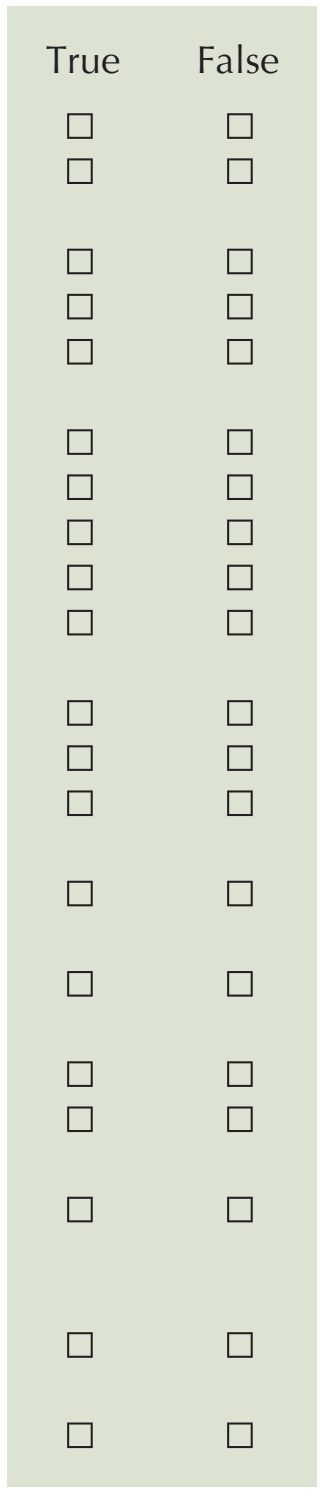

\section{Doctor's particulars:}

Name in full

MCR number

Email address

\section{SUBMISSION INSTRUCTIONS:}

(1) Visit the SMJ website: http://www.smj.org.sg/current-issue and select the appropriate set of questions. (2) Provide your name, email address and MCR number. (3) Select your answers and click "Submit".

\section{RESULTS:}

(1) Answers will be published online in the SMJ February 2017 issue. (2) The MCR numbers of successful candidates will be posted online at the SMJ website by 2 February 2017. (3) Passing mark is $60 \%$. No mark will be deducted for incorrect answers. (4) The SMJ editorial office will submit the list of successful candidates to the Singapore Medical Council.

(5) One CME point is awarded for successful candidates.

Deadline for submission: (December 2016 SMJ 3B CME programme): 12 noon, 26 January 2017. 